\title{
Removal of Moisture Content in Paper Machine Using Soft Computing Techniques
}

\author{
M. Senthil Kumar1, K. Mahadevan² \\ ${ }^{1}$ Department of Electrical and Electronics Engineering, Syed Ammal Engineering College, Landhai, \\ Tamil Nadu, India \\ ${ }^{2}$ Department of Electrical and Electronics Engineering, PSNA College of Engineering and Technology, \\ Dindigul, Tamil Nadu, India \\ Email: msenthilkumar040682@gmail.com
}

Received 9 May 2016; accepted 18 May 2016; published 27 July 2016

Copyright ( 2016 by authors and Scientific Research Publishing Inc.

This work is licensed under the Creative Commons Attribution International License (CC BY).

http://creativecommons.org/licenses/by/4.0/

(c) (i) Open Access

\begin{abstract}
The choice of this investigation is to tune the proportional-integral-derivative (PID) parameters separately for controlling the moisture content in paper industry by using Particle Swarm Optimization (PSO). This paper boon a new algorithm for PID controller tuning based particle swarm optimization. PSO algorithm has recently developed as a very powerful method for real parameter optimization. This new process is proposed to combine both the algorithms to get better optimization values. The proposed algorithm tuned the PID parameters and its performance has been compared with PID algorithm. Compared to PID algorithm technique, dynamic performance requirements such as rise time settling time and peak overshoot optimal values produced by PSO. The plant model represented by the transfer function is obtained by the system identification toolbox.
\end{abstract}

\section{Keywords}

PID Controller, Particle Swarm Optimization, Industrial Application

\section{Introduction}

In current times, paper is one of the basic materials, normally found around all part of the world. The role of a paper machine is to form the paper sheet and remove the water from the paper sheet. A paper machine is divided into three main divisions, the wire section, the press section and the drying section [1]-[9]. Figure 1 signifies the block diagram of paper procedure and removal of moisture in various stages. When the paper travels on the wire, much of the water gets drained away by gravitational forces or is pulled away by suction from underneath. As 


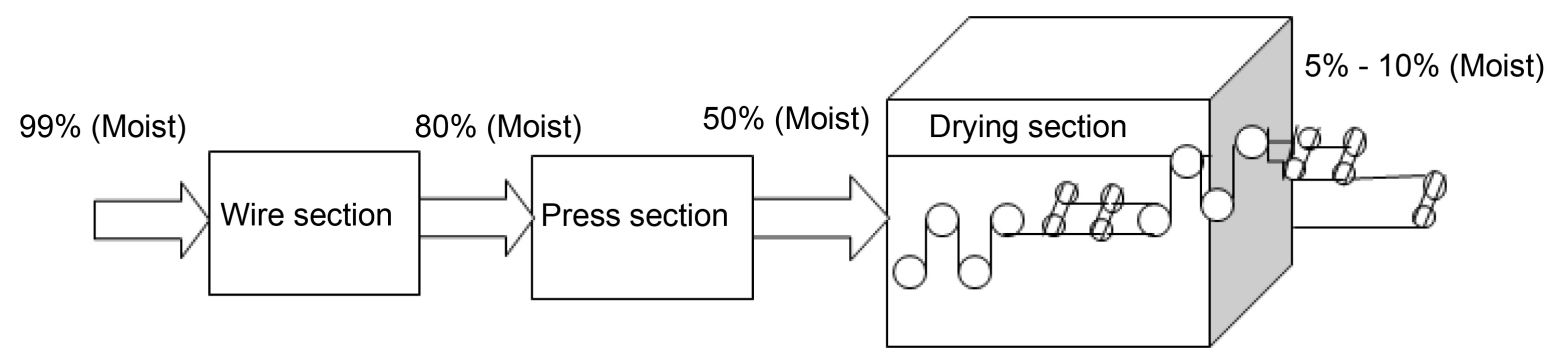

Figure 1. Principle of paper production.

the water goes, the cellulose fibres start to adhere to one another by hydrogen bonds and form a paper web. When the paper web leaves the wire section and enters the press section, the dry solid content is around $20 \%$. In the press section, the newly formed sheet is pushed between rotating steel rolls and water is banished into a press belt. After a few press nips, the web enters the drying section with a solid content of approximately 50\%. It now encounters the dryer cylinders. The dyer cylinders are enormous hollow metal cylinders, heated internally with steam, which dry the paper as it passes through them. Lastly, the paper is wound up on a big roll and separate from the paper machine. The moisture content is now roughly about 5\% - 10\%. Many properties of paper such as curl, stretch, tear, strength and stiffness depend on moisture content. So far drying section is concerned, it is liable for removing less than $1 \%$ of the water volume from the original stock to the head box; this is the part of the paper machine that, by far, consumes maximum energy. In the treating of moisture, most of the variations can adversely affect the future processing units like calendaring, converting (or) packaging line or even the printing press of customer. At the time of manufacture, the content of moisture is therefore measured and monitored online and if it deviates outside of the specified limits, the product of paper is rejected. During usual operation, stable and uniform moisture content guarantees a low rejection and consequently high production rate. The current day paper machine provides around 1000 tons of paper per day. A reduction of moisture around $0.1 \%$ corresponds to 365 tons of raw material per annum. A well-tuned moisture control system will reduce the time to carry out a grade change (state transition). In practice, the moisture feedback loop is often turned off during a grade change and the process is run in open loop (feed forward). The moisture control loop is indirectly involved during a web break by the steam pressure in the steam cylinders. A very common problem is that the cylinders become exciting since there is no longer any possibility of cooling paper around them. When the paper web is put back, picking and breakage of new web easily occur. A new tuning method is developed for both PID and PI controllers based on optimization of moisture. It is compared to a few other design methods and tested on a real paper machine. The objective of the proposed work is to develop a soft computing based PID tuning methodology for optimizing the control of moisture in paper machine. It proposes the development of a tuning technique which would be best suitable for optimizing the MD control of processes operating in a single-input-singleoutput process control loop. The SISO topology has been selected for this study because it is the most fundamental control loop and the theory developed for this type of loop can be easily extended to more complex loop. In this approach the transfer function of moisture process was determined using system identification tool box in MATLAB which is utilized for the soft computing based tuning simulation. The PID tuning parameters are determined from the soft computing methodology. PID controller is well-suited for industrial application.

\section{Machine Direction (MD) Moisture Control}

The quality control system (QCS) is divided in two separate dimensions, the machine direction control (MD) and the cross direction control (CD).The conventional technique is to measure the MD and CD signals by scanning the sheet with a single sensor. The sensor is mounted in a scanner platform, where it moves back and forth in the cross direction (see Figure 2). The primary mechanism today for the control of the moisture MD variations is the dryer steam pressure. The moist paper can be led around a single large steam heated cylinder, called Yankee cylinder (mainly used for the drying of tissue) or a large number of steam heated cast iron cylinders in series (commonly called cans), called multi-cylinder drying. The purpose of the steam and condensate system is to provide a sufficient amount of steam to the dryers and to handle the condensed steam. The cylinders in a drying section are divided in separate dryer groups, normally between five and ten groups. The steam pressure in 


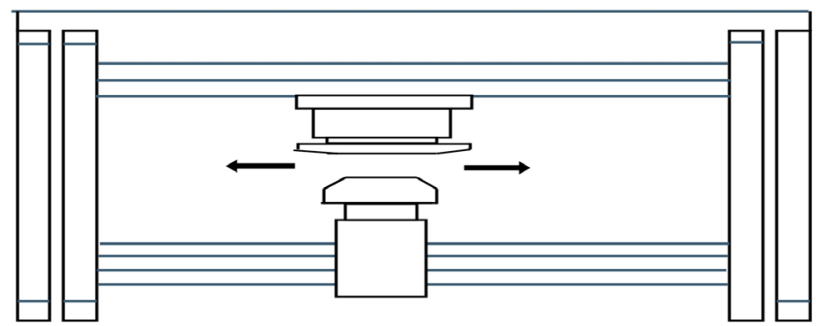

Figure 2. Quality control scanner moves the sensor back and forth across the sheet by courtesy of ABB Ltd.

the different dryer groups can then be controlled individually go obtain the desired pressure profile through the drying section, from the first group to the last one. Since the steam inside the cylinder can be regarded as saturated because of the continuous condensation at the cylinder wall, there is a direct correlation between the steam pressure and steam temperature and you could also talk about a temperature profile. For most paper grades, dryer steam pressure is increased gradually for drying capacity and run ability reasons. The modelled system is represented in the Equation (1).

$$
\frac{0.978 \exp (-1.976 s)}{5.18 s^{2}+5.016 s+1}
$$

\section{Materials and Methods}

\subsection{Design of PID Controller}

During the past few decades, process control techniques in the industry have made great advancement. Many process control methods based on adaptive control, predictive control, neural control and fuzzy control have been studied. Despite many efforts, the Proportional-Integral-Derivate (PID) controller continues to be the main component in industrial control system, including embedded controllers, programmable logic controllers and distributed control systems. The reason is that it has a simple structure easily understood by the engineers and it gives robust performance in a wide range of operating conditions [10]. PID controller has become inevitable in the process control industries due to its simplicity and effectiveness, but the real challenge lies in tuning already exist, there is still a need for an advanced system for tuning these controllers. There is a lot to be gained with the optimization of control loops. It has been estimated that $80 \%$ of process control loops cause more variability when they run in automatic mode than in manual mode. About $30 \%$ of all loops oscillate due to nonlinearities such as hysteresis, stiction, dead band, and non-linear process gain. Another 30\% oscillate because of poor controller tuning. When a loop is poorly optimized, an upset in the direction of inefficiency can cause production losses. Alternatively, a load can lead to the production of off-spec products. When a control loop is run optimally, variability is minimized. A better tuning keeps the process on specification and reduces the waste of often expensive ingredients. Once the transfer function model was found the controller must be calculated in a way so that the system continues at optimal set point and this was made practicable by the optimal of tuning parameters $K_{p}, K_{i}$ and $K_{d}$ for a PID Controller [11]-[22]. These controllers are generally designed on the basis of linear control theory, even though the system is nonlinear in nature. This paper concerns about evaluation of an optimal controller design at ease by means of Particle Swarm Optimization. The PID gain values are projected via conventional Z-N tuning method and the corresponding optimum value of gain is found with heuristic algorithm. Heuristic Methods can be suitable for higher order systems without model reduction.

The general PID equation represents in the Equation (2)

$$
U(t)=K_{p} \times e(t)+K_{i} \int e(t) \mathrm{d} t+K_{d} \times \frac{\mathrm{d} e(t)}{\mathrm{d} t}
$$

$K_{p}=$ proportional gain, $K_{i}=$ integral time and $T_{d}=$ derivative time.

\subsection{Tuning of PID Using PSO}

The PSO approach has superior feature, including easy implementation, stable convergence characteristic and 
very good computational performance efficiency [23]. Modeling of the DC Motor with PID-PSO controller was simulated in MATLAB environment. Comparing with fuzzy logic number, PSO intelligent algorithms are more proficient in improving the speed loop response stability, reducing the steady state error and the rise time [24]. In the study, the real-time responses of a position servo system employing both online and offline tuning are presented. For off-line tuning a process model was obtained using the MATLAB model identification toolbox. This model is then imparted in the simulation studies to determine the tuning parameters using different tuning methods. For on-line tuning the parameters for the GA and PSO approach are obtained directly from the offline plant. For both tests it is found that the PSO method outperformed all other tuning methods. The brushless DC motor is modeled in Simulink and the PSO algorithm is implemented in MATLAB environment. Comparing with Genetic Algorithm (GA) and Linear Quadratic Regulator method, the proposed method is more efficient in improving the step response characteristics such as, reducing the steady-states errors, rise time, settling time and maximum overshoot and thus effectively controls the speed of a linear brushless DC motor .In the Literature [25], the various results that prove the battens of the PSO tuned PI settings than the IMC tuning has been discussed. The simulation response for the models validated reflects the effectiveness of the PSO based controller in terms of time domain specifications. The performance indices under the various error criterions for the proposed controller are always less that the IMC tuned controller. Above all, the real time response confirms the validity of the proposed PSO based tuning for the conical tank. The algorithm proposed by Eberhart and Kennedy uses a 1-D approach for searching within the solution space. For this study the PSO algorithm will be applied to a 2-D or 3-D solution space in search of optimal tuning parameters for PID, PI and PD control [26]. The flowchart of the PSO PID control system is shown in Figure 3. Consider position $X_{i, m}$ of the i-th particle as it traverses a n-dimensional search space: The previous best position for this i-th particle is recorded and represented as pbest $t_{1, \mathrm{n}}$. The best performing particle among the swarm population is denoted as gbest $\mathrm{I}_{\mathrm{I}, \mathrm{n}}$ and the velocity of each particle within the n-dimension is represented as $V_{i, n}$. The new velocity and position for each particle can be calculated from its current velocity and distance respectively. So far (pbest) and the position in the d-dimensional space. The velocity of each particle, adjusted accordingly to its own flying experience. In the proposed PSO method each particle contains three members P, I and D. It means that the search space has three dimension and particles must "fly" in the three dimension space.

For the PID-controlled system, there are often only one indices to represent the system performance: IAE. They are defined as follows in Equation (3)

$$
\operatorname{IAE}=\int_{0}^{\infty}|e(t)| \mathrm{d} t
$$

The major objective of this work is to test the performance of the developed particle swarm optimization algorithm by tuning the PID controller. Attempt has been made to achieve globally minimal Absolute error in step response of a process which is cascaded with PID controller by tuning the $K_{p}$ proportional gain, $K_{d}$ differential gain and $K_{i}$ integral gain values and compute the integral absolute error. In PSO tuning of PID controller, best possible value of $\left[k_{p}, k_{i}\right.$ and $\left.k_{d}\right]$ are obtained which exhibits less overshoot, has a reasonable level of settling time, low rise time and zero steady state error

\section{Results and Discussion}

The paper machine is modeled with moisture content control loop by using DCS. The transfer function is obtained to validate the moisture control process with the real time data. The mathematical model of the system is to be analyzed as a closed-loop system. By selecting the process model with poles and delay, the real time data has been estimated and validated. In this paper a time domain criterion is used for evaluating the PID controller. A set of control parameters P, I, and D can yield a good step response that will results in minimization of performance criteria in the time domain. The performance criteria in the time domain includes the over shoot, rise time and setting time. To control the plant model, PID and PSO techniques are used to verify the performance of the PID controller Parameters. Among these techniques, PSO based tuning methods have proved their excellence in giving better results by improving the time domain specifications and performance indices. Figures 4-7 represents the System identification tool box, Noise spectrum, Model output and Data model. The output response of PSO and PID are shown in Figure 8 \& Figure 9. Technical Specifications of Paper Machine are shown in Table 1. The comparison results are shown in Table 2. 


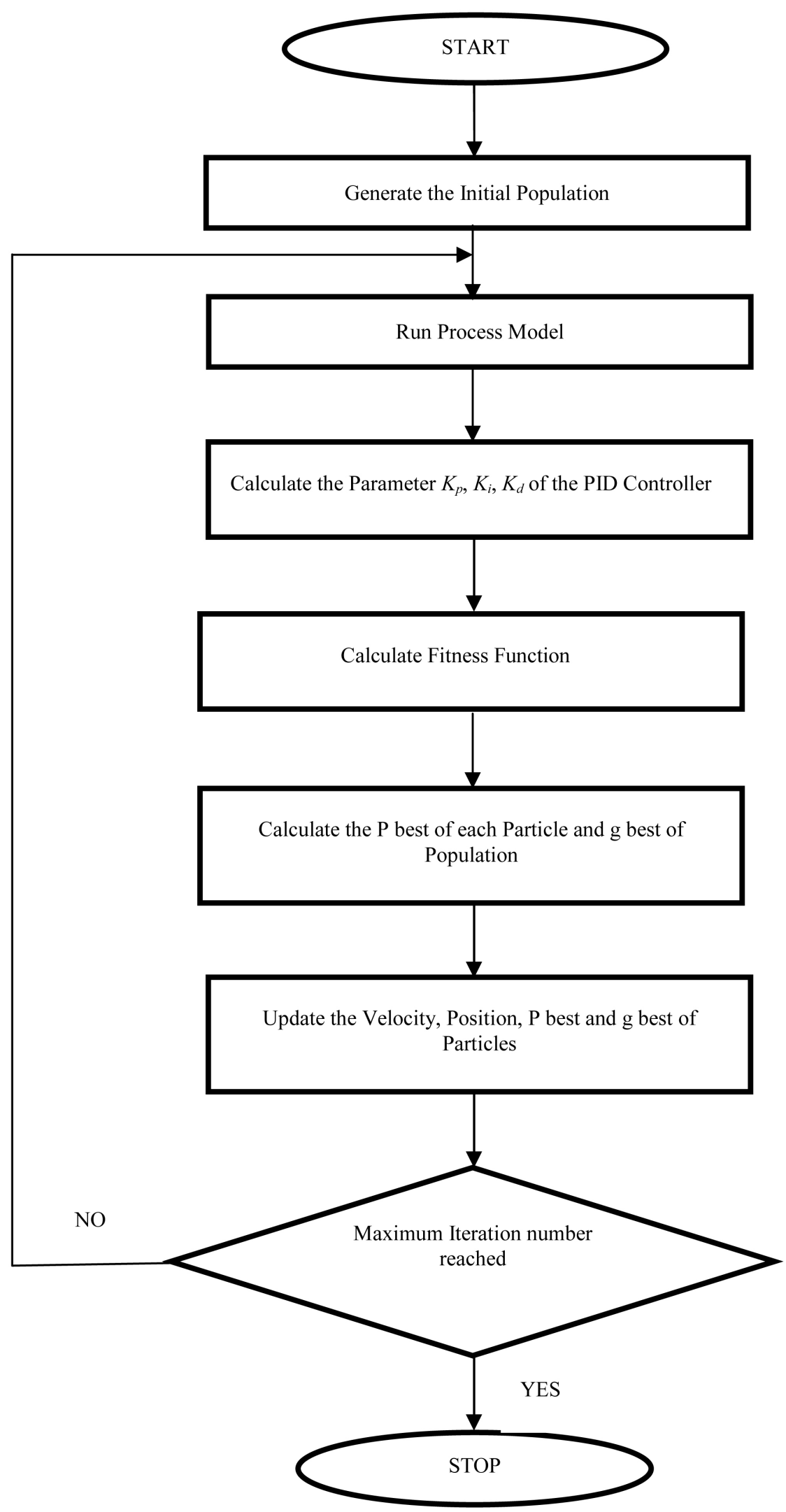

Figure 3. Flow chart of PSO. 


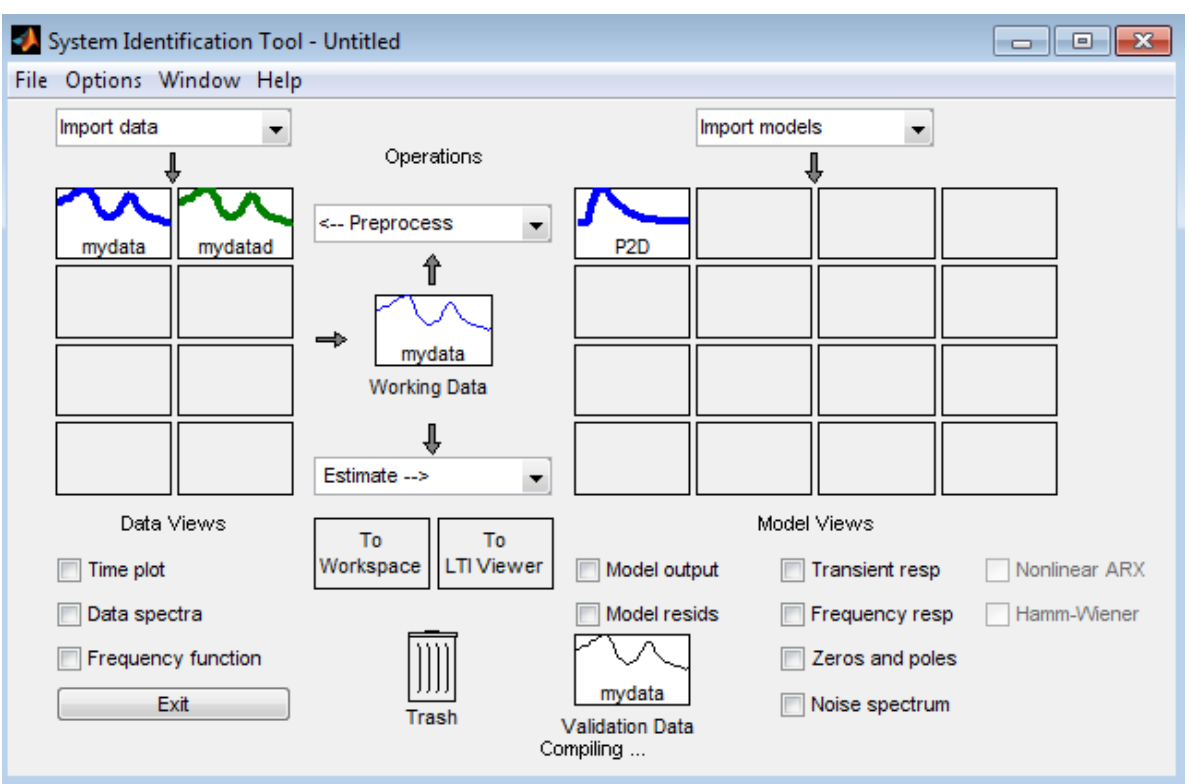

Figure 4. System identification tool box.

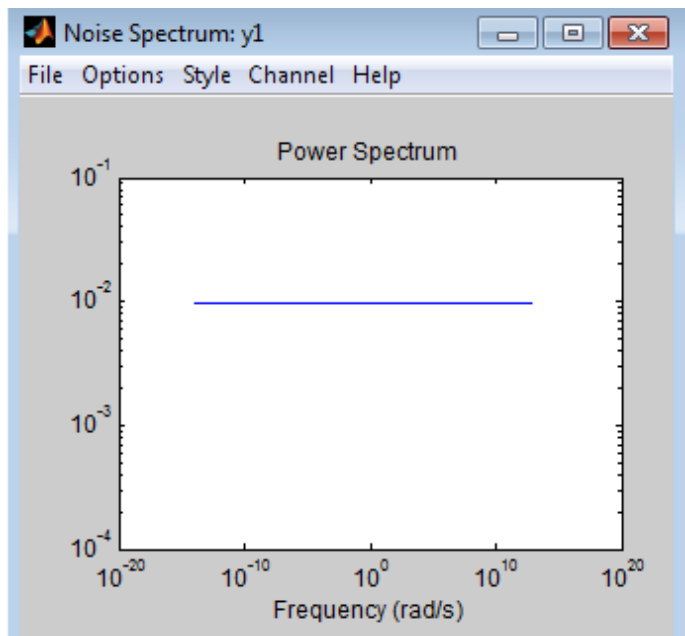

Figure 5. Noise spectrum.

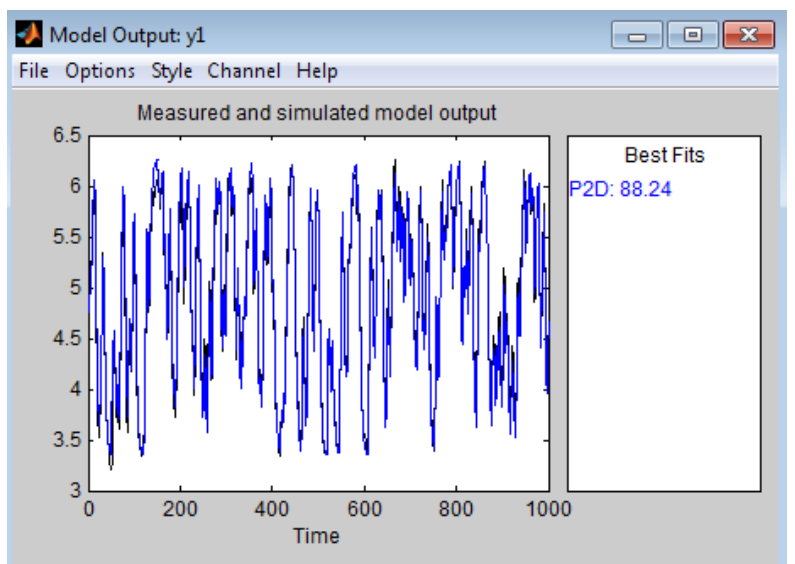

Figure 6. Model output. 


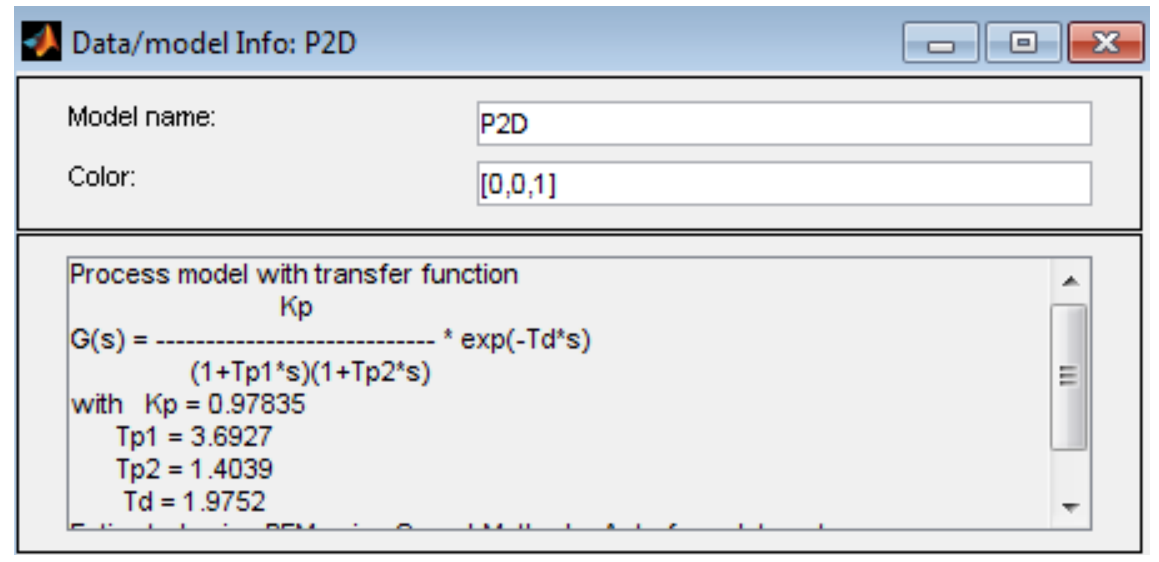

Figure 7. Data model.

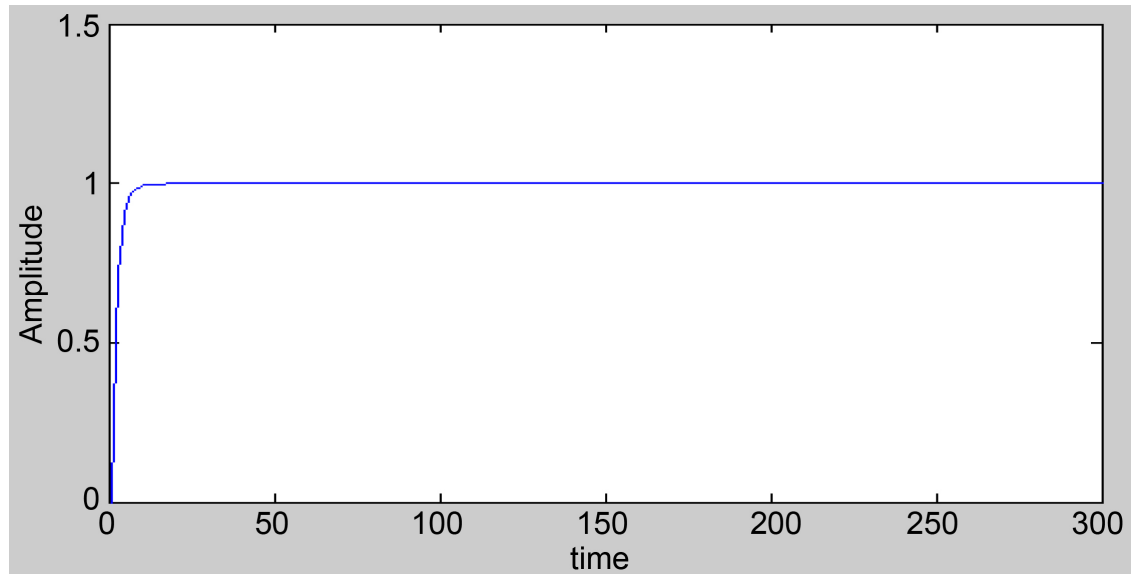

Figure 8. Response of PSO controller.

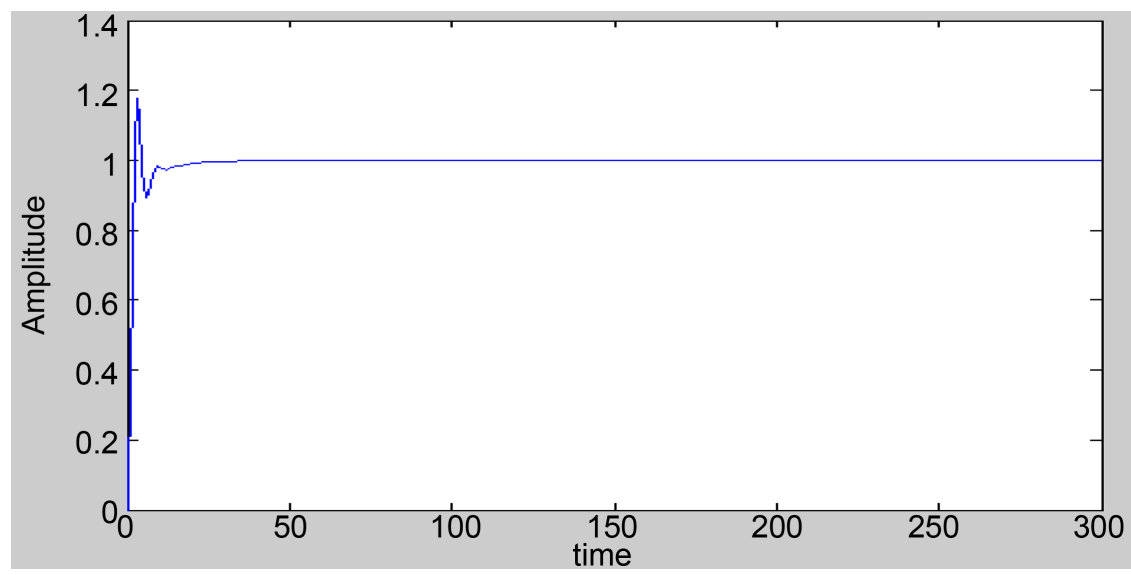

Figure 9. Response of PID controller.

\section{Conclusion}

In this work, optimal PID tuning is obtained by using PSO. Simulation results demonstrate the tuning method which in this paper has provided better control performance compared with the conventional ones. Approximations that are typical to classical tuning rules are not needed. Soft computing techniques are often criticized for two reasons: algorithms are computationally heavy and convergence to the optimal solution cannot be guaranteed. 
Table 1. Technical specifications of paper machine.

\begin{tabular}{cc}
\hline Components & Technical Specifications \\
DCS System & AC 450 Controller \\
AC 450 Controller & AI-4-20 MA, AO-4-20 MA \\
AMPL-Programming \\
Quality Control Scanner & Moisture-IR Sensor \\
Control Valve & Output-(4-20 MA) Honey Well make \\
Size:6”, Pneumatic actuated & Type: Air to Open \\
I/P Converter & Input-4-20 MA; Output-0-6 Bar \\
Dryer & 43 Cylinders, 5 Groups; Material-Milled \\
Steam Pressure & Steel \\
Steam Temperature & 3.5 Bar to 4.5 Bar \\
Day Production \& Machine Speed & 150C to 180C \\
\hline
\end{tabular}

\section{Table 2. Comparison results.}

\begin{tabular}{|c|c|c|c|c|c|c|}
\hline \multirow{2}{*}{$\begin{array}{l}\text { Tuning } \\
\text { Method }\end{array}$} & \multicolumn{2}{|c|}{ PID Parameter } & \multicolumn{3}{|c|}{$\begin{array}{c}\text { Dynamic } \\
\text { Performance Specifications }\end{array}$} & \multirow{2}{*}{$\begin{array}{c}\text { Performance } \\
\text { Index }\end{array}$} \\
\hline & $\begin{array}{c}\mathrm{Kp} \\
\text { (Proportional } \\
\text { gain) }\end{array}$ & $\begin{array}{c}\mathrm{Ki} \\
\text { (Integral } \\
\text { gain) }\end{array}$ & $\begin{array}{c}\mathrm{Tr} \\
\text { (Rise time) }\end{array}$ & $\begin{array}{c}\text { Ts } \\
\text { (Settling } \\
\text { time) }\end{array}$ & $\begin{array}{c}\text { Mp (\%) } \\
\text { (Peak } \\
\text { overshoot) }\end{array}$ & \\
\hline PID & 6 & 0.7 & 2.1648 & 26.8930 & 17.4868 & 2 \\
\hline PSO & 5.34542 & 6.86754 & 0.56423 & 4.3456 & 0 & 1.43545 \\
\hline
\end{tabular}

PID controller tuning is a small-scale problem in which computational complexity is not an issue. It took only a couple of seconds to solve the problem. Compared to conventionally tuned system, PSO tuned system has good steady state response and performance indices.

\section{References}

[1] Heo, C.H., Cho, H. and Yeo, Y.-K. (2011) Dynamic Modelling of Paper Drying Processes. Korean Journal of Chemical Engineering, 28, 1651-1657. http://dx.doi.org/10.1007/s11814-011-0046-0

[2] Slätteke, O. (2006) Modeling and Control of the Paper Machine Drying Section. Thesis, Lund University, Lund.

[3] Austin, P.C., Mack, J., McEwan, M., Afshar, P., Brown, M. and Maciejowski, J. (2011) Improved Energy Efficiency in Paper Making through Reducing Dryer Steam Consumption Using Advanced Process Control. PaperCon, 1, 11221132.

[4] Goyal, S. and Kumar, R. (2013) ANN Control of Paper Drying Process. International Journal of Application or Innovation in Engineering \& Management, 2, 100-107.

[5] Karthik, C., Valarmathi, K. and Raja Lakshmi, M. (2012) Nonlinear Modelling of Moisture Control of Drying Process in Paper Machine. Procedia Engineering, 38, 1104-1111. http://dx.doi.org/10.1016/j.proeng.2012.06.139

[6] Sajwan, N. and Rajesh, K. (2011) Artificial Neural Network Modeling for Tensile Strength of Paper in Paper Manufacturing Process. International Journal of Information Technology and Knowledge Management, 4, 409-412.

[7] Yeo, Y.-K., Hwang, K.-S., Yi, S.C. and Kang, H. (2004) Modeling of the Drying Process in Paper Plants. Korean Journal of Chemical Engineering, 21, 761-766. http://dx.doi.org/10.1007/BF02705517

[8] Zvolinschi, A., Johannessen, E. and Kjelstrup, S. (2006) The Second-Law Optimal Operation of a Paper Drying Machine. Chemical Engineering Science, 61, 3653-3662. http://dx.doi.org/10.1016/j.ces.2005.12.030

[9] Lu, T. and Shen, S.Q. (2007) Numerical and Experimental Investigation of Paper Drying: Heat and Mass Transfer with Phase Change in Porous Media. Applied Thermal Engineering, 27, 1248-1258. http://dx.doi.org/10.1016/j.applthermaleng.2006.11.005

[10] Astrom, K.J. and Hagglund, T. (1995) PID Controllers Theory, Design and Tuning. 
[11] Venugopal, P., Ganguly, A. and Singh, P. (2013) Design of Tuning Methods of PID Controller Using Fuzzy Logic. International Journal of Emerging Trends in Engineering and Development, 5, 239-248.

[12] Tang, K.S., Man., K.F., Chen, G. and Kwong, S. (2001) An Optimal Fuzzy PID Controller. IEEE Transactions on Industrial Electronics, 48, 757-765. http://dx.doi.org/10.1109/41.937407

[13] Ziegler, J.G., Nichols, N.B. and Rochester, N.Y. (1942) Reprint of Optimum Settings for Automatic Controllers. Transactions of the A.S.M.E, 759-765.

[14] Sharifian, M.B.B., Rahnavard, R. and Delavari, H. (2009) Velocity Control of DC Motor Based Intelligent Methods and Optimal Integral State Feedback Controller. International Journal of Computer Theory and Engineering, 1, 17938201.

[15] Ko, C.-N. and Wu, C.-J. (2007) A PSO-Tuning Method for Design of Fuzzy PID Controllers. Journal of Vibration and Control, 14, 375-395. http://dx.doi.org/10.1177/1077546307080038

[16] Harinath, E. and Mann, G.K.I. (2008) Design and Tuning of Standard Additive Model Based Fuzzy PID Controllers for Multivariable Process Systems. IEEE Transactions on Systems, Man, and Cybernetics-Part B: Cybernetics, 38, 667-674. http://dx.doi.org/10.1109/TSMCB.2008.919232

[17] Li, K. (2013) PID Tuning for Optimal Closed-Loop Performance with Specified Gain and Phase Margins. IEEE Transactions on Control Systems Technology, 21, 1024-1030. http://dx.doi.org/10.1109/TCST.2012.2198479

[18] Seng, T.L., Khalid, M.B. and Yusof, R. (1999) Tuning of a Neuro-Fuzzy Controller by Genetic Algorithm. IEEE Transactions on Systems, Man, and Cybernetics-Part B: Cybernetics, 29, 226-236. http://dx.doi.org/10.1109/3477.752795

[19] Kim, K., Rao, P. and Burnworth, J.A. (2010) Self-Tuning of the PID Controller for a Digital Excitation Control System. IEEE Transactions on Industry Applications, 46, 1518-1524. http://dx.doi.org/10.1109/TIA.2010.2049631

[20] Milanés, V., Villagrá, J., Godoy, J. and González, C. (2012) Comparing Fuzzy and Intelligent PI Controllers in Stopand-Go Manoeuvres. IEEE Transactions on Fuzzy Systems, 20, 770-778. http://dx.doi.org/10.1109/tcst.2011.2135859

[21] Du, X. and Ying, H. (2010) Derivation and Analysis of the Analytical Structures of the Interval Type-2 Fuzzy-PI and PD Controllers. IEEE Transactions on Fuzzy Systems, 18, 802-814. http://dx.doi.org/10.1109/TFUZZ.2010.2049022

[22] Neath, M.J., Swain, A.K., Madawala, U.K. and Thrimawithana, D.J. (2014) An Optimal PID Controller for a Bidirectional Inductive Power Transfer System Using Multiobjective Genetic Algorithm. IEEE Transactions on Power Electronics, 29, 1523-1531. http://dx.doi.org/10.1109/TPEL.2013.2262953

[23] Nasri, M., Nezamabadi-Pour, H. and Maghfoori, M. (2007) A PSO-Based Optimum Design of PID Controller for a Linear Brushless DC Motor. International Journal of Electrical, Computer, Energetic, Electronic and Communication Engineering, 1, 171-175.

[24] Allaoua, B., Gasbaoui, B. and Mebarki, B. (2009) Setting up PID DC Motor Speed Control Alteration Parameters Using Particle Swarm Optimization Strategy. Leonardo Electronic Journal of Practices and Technologies, 19-32.

[25] Girirajkumar, S.M., Sivasankaran, R., Radhakrishnan, T.K., Dharmalingam, V. and Anantharaman, N. (2008) Particle Swarm Optimization Technique Based Design of Pi Controller for a Real Time Nonlinear Process. Instrumentation Science \& Technology, 36, 525-542. http://dx.doi.org/10.1080/10739140802234980

[26] Ko, C.-N. and Wu, C.-J. (2007) A PSO-Tuning Method for Design of Fuzzy PID Controllers. Journal of Vibration and Control, 14, 375-395. http://dx.doi.org/10.1177/1077546307080038

\section{Submit or recommend next manuscript to SCIRP and we will provide best service for you:}

Accepting pre-submission inquiries through Email, Facebook, LinkedIn, Twitter, etc.

A wide selection of journals (inclusive of 9 subjects, more than 200 journals)

Providing 24-hour high-quality service

User-friendly online submission system

Fair and swift peer-review system

Efficient typesetting and proofreading procedure

Display of the result of downloads and visits, as well as the number of cited articles

Maximum dissemination of your research work

Submit your manuscript at: http://papersubmission.scirp.org/ 